\title{
The antimicrobial compound reuterin (3- hydroxypropionaldehyde) induces oxidative stress via interaction with thiol groups
}

\author{
Laura Schaefer, ${ }^{1}$ Thomas A. Auchtung, ${ }^{1}$ Karley E. Hermans, ${ }^{1}$ \\ Daniel Whitehead, ${ }^{2}$ Babak Borhan ${ }^{2}$ and Robert A. Britton ${ }^{1}$ \\ ${ }^{1}$ Department of Microbiology and Molecular Genetics, Michigan State University, East Lansing, \\ MI 48824, USA \\ ${ }^{2}$ Department of Chemistry, Michigan State University, East Lansing, MI 48824, USA
}

Correspondence

Robert A. Britton

rbritton@msu.edu

Received 18 October 2009

Revised 15 January 2010

Accepted 9 February 2010

\section{INTRODUCTION}

The use of probiotic bacteria to improve human and animal health has enjoyed a renaissance in the past decade. Companies in the food and dietary supplement industries have increasingly been adding probiotic strains to several different products and touting a variety of health benefits associated with these foods. Recent clinical trials have shown that probiotics are effective in treating a variety of ailments, including diarrhoea, colic, eczema and pouchitis (Floch et al., 2008; Savino et al., 2007; Wickens et al., 2008). However, most of these trials are small, and to date few well-controlled large-scale clinical trials have been conducted, so the efficacy of probiotics in many diseases remains to be proven.

A number of mechanisms by which probiotics exert their beneficial effects have been proposed, including the modulation of the immune system, the alteration of the

Abbreviations: DTNB, 5,5'-dithiobis-(2-nitrobenzoic acid); 3-HPA, 3hydroxypropionaldehyde; TNB, 5-thio-2-nitrobenzoic acid.

The microarray data discussed in this paper are available from the Gene Expression Omnibus (GEO) under accession number GSE19760.

A supplementary table, listing $E$. coli genes induced and repressed upon exposure to reuterin, is available with the online version of this paper. intestinal microbiota, and the production of antimicrobial compounds that inhibit the growth of pathogens (Marco et al., 2006; O'Hara \& Shanahan, 2007). Understanding the mechanisms that are actively contributing to the beneficial effects of probiotics will be an important step in tapping the true potential of these organisms in benefiting health.

Strains of Lactobacillus reuteri have been shown to be effective against a variety of ailments, including diarrhoea and colic (Rosenfeldt et al., 2002a, b; Savino et al., 2007; Weizman et al., 2005). One of the proposed mechanisms of action that $L$. reuteri uses to effect probiosis is the production of the antimicrobial compound 3-hydroxypropionaldehyde (3-HPA), also referred to as reuterin (Talarico et al., 1988). Reuterin is produced as an intermediate step in the conversion of glycerol to 1,3propanediol, a pathway proposed to regenerate $\mathrm{NAD}^{+}$ from NADH and to contribute to improved growth yield (Luthi-Peng et al., 2002). Reuterin is metabolized in a specialized bacterial compartment called the metabolosome, perhaps due to its toxicity (Sriramulu et al., 2008). For reasons that are unclear, $L$. reuteri secretes high levels of reuterin when grown or incubated in the presence of excess amounts of glycerol. Reuterin has been shown to be bioactive against bacteria, viruses and fungi (Chung et al., 
1989; Cleusix et al., 2007), and has been studied as a possible additive to prevent food spoilage and pathogen growth in food (Arques et al., 2004, 2008). Recent work using germ-free mice mono-associated with a reuterinproducing strain of $L$. reuteri has demonstrated that reuterin can be produced by $L$. reuteri in vivo, indicating that the in vitro antimicrobial activity occurs in the gastrointestinal tract (Morita et al., 2008).

The aldehyde group of reuterin is highly reactive and thus reuterin can form additional compounds in aqueous solution (Vollenweider \& Lacroix, 2004). Reuterin can dimerize, forming HPA dimer, or can be hydrated to form HPA hydrate (Fig. 1). Reuterin can also be dehydrated into the toxic compound acrolein. Because reuterin can be converted into these various compounds, the mechanism by which reuterin exerts its antimicrobial effects has been difficult to determine. Two main hypotheses have been proposed. First, the aldehyde group of reuterin is proposed to be highly reactive with thiol groups and primary amines, and therefore reuterin could inactivate proteins and small molecules containing these groups (Vollenweider \& Lacroix, 2004). This would explain the broad spectrum of bacteria, fungi and viruses affected by reuterin. Alternatively, the dimeric form of reuterin, HPA dimer, which is structurally similar to a ribose sugar, could specifically block the enzyme ribonucleotide reductase by acting as a competitive inhibitor. This enzyme is required for the generation of deoxynucleotides, which are required for DNA synthesis. An earlier report has suggested that reuterin could indeed inhibit ribonucleotide reductase and possibly exert its broad-spectrum effects through this inhibition (Talarico \& Dobrogosz, 1989). Because the active site of this enzyme contains a thiol group, it is impossible to determine which proposed mode of action is correct from earlier experiments.

We were interested in further exploring the expression of reuterin in $L$. reuteri as well as its mode of action. Our work demonstrates that reuterin is produced solely by the

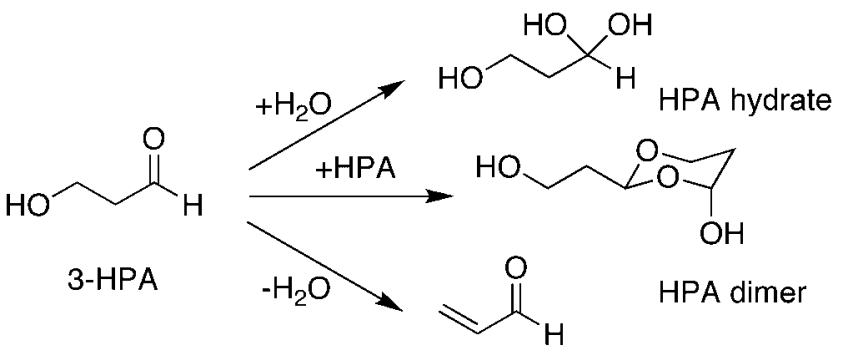

Acrolein

Fig. 1. 3-HPA (reuterin) can adopt a number of different forms, as indicated in the main text. 3-HPA can react with water to form HPA hydrate or interact with itself to form HPA dimer (normally seen only at very high 3-HPA concentrations). 3-HPA can also undergo dehydration to form acrolein. enzyme glycerol dehydratase and that direct contact with other bacteria can stimulate reuterin production or secretion. Several lines of in vivo and in vitro evidence indicate that the aldehyde form of reuterin is the bioactive agent and that this causes an oxidative stress response by modifying thiol groups inside cells.

\section{METHODS}

Bacterial strains, media, and growth conditions. Strains used in this study are listed in Table 1 . L. reuteri was grown in liquid culture under hypoxic conditions $\left(2 \% \mathrm{O}_{2}, 5 \% \mathrm{CO}_{2}\right.$, balanced with $\left.\mathrm{N}_{2}\right)$ in de Man, Rogosa and Sharpe (MRS) broth (BD Difco). L. reuteri was also grown on plates under anaerobic conditions using the GasPak EZ anaerobe Container System (BD Difco) on MRS agar (BD Difco) at $37{ }^{\circ} \mathrm{C}$ for $24-48$ h. L. reuteri mutants were grown in the presence of $10 \mu \mathrm{g}$ erythromycin $\mathrm{ml}^{-1}$. Bacillus subtilis, Citrobacter rodentium and Escherichia coli strains were grown in liquid culture in LB broth (BD Difco) at $37{ }^{\circ} \mathrm{C}$ under aerobic conditions. Clostridium difficile strain CD630 was grown in brain heart infusion media (Fluka) supplemented with yeast extract $\left(5 \mathrm{mg} \mathrm{ml}^{-1}, \mathrm{BD}\right.$ Difco) under anaerobic conditions in a Coy Laboratory anaerobic chamber.

Reuterin production and purification. Reuterin was produced from $L$. reuteri cultures using methods described elsewhere (Talarico \& Dobrogosz, 1989; Vollenweider et al., 2003). Briefly, cells were harvested from liquid cultures of $L$. reuteri by centrifugation and washed twice with $50 \mathrm{mM}$ sodium phosphate buffer ( $\mathrm{pH} 7.4$ ). Approximately $150 \mathrm{mg}$ cells (wet weight) were resuspended in $15 \mathrm{ml} 250 \mathrm{mM}$ glycerol and transferred to $15 \mathrm{ml}$ screw-capped tubes; if needed, the appropriate amount of other bacteria was added as described below. The cells in glycerol were incubated at $37^{\circ} \mathrm{C}$ for $2 \mathrm{~h}$. Reuterin was collected by pelleting the cells and filtering the supernatants through $0.22 \mu \mathrm{m}$ pore-size filters (Millipore). The resulting cell-free supernatant was shown by HPLC to contain only reuterin and glycerol (see Methods, HPLC, below).

Reuterin quantification and activity. Reuterin was quantified using an adapted colorimetric assay described by Doleyres et al. (2005); reuterin samples were diluted 10 -fold in water and the $A_{560}$ was determined on a Spectramax model M5 microplate reader (Molecular Devices). The antimicrobial activity of reuterin was quantified using a MIC assay described by Chung et al. (1989) and adapted for use in a 96-well format. Relative reuterin concentration (units reuterin $\mathrm{ml}^{-1}$ ) was defined as the reciprocal of the sample dilution preceding the dilution that allowed cell growth. E. coli $\mathrm{DH} 5 \alpha$ cells were grown overnight at $37^{\circ} \mathrm{C}$ in $\mathrm{LB}$ broth and diluted to approximately $10^{4}$ cells $\mathrm{ml}^{-1}$. Twofold serial dilutions of reuterin-containing cell-free supernatant samples were prepared with water in 96-well $0.4 \mathrm{ml}$ deep-well flat-bottomed plates (Nalge Nunc) in a total volume of $150 \mu \mathrm{l}$ per well. A $150 \mu \mathrm{l}$ volume of the E. coli suspension was added to each well and the plates were incubated aerobically at $37^{\circ} \mathrm{C}$ overnight. Water was assayed in place of reuterin as a positive growth control. $\mathrm{OD}_{600}$ values were measured in a Spectramax model M5. The absence of a turbid culture after overnight growth was interpreted as growth inhibition by reuterin. For the experiments assaying reuterin activity in the presence of cysteine, valine or serine, each amino acid (Sigma-Aldrich) was added to each well to a final concentration of $600 \mu \mathrm{M}$.

Microarray experiments. Oligonucleotide microarrays for E. coli were obtained from T. Whittam (Michigan State University, East Lansing, MI) (Bergholz et al., 2007). The microarrays were printed onto Corning UltraGap slides at the Research Technology Support Facility at Michigan State University using E. coli oligonucleotide set 
Table 1. Strains used in this study

\begin{tabular}{|c|c|c|}
\hline Strain & Description & Source or reference \\
\hline \multicolumn{3}{|l|}{ L. reuteri strains } \\
\hline ATCC 23272 & Type strain, isolated from human faeces & BioGaia \\
\hline ATCC 55730 & Isolated from human breast milk & BioGaia \\
\hline PRB90 & $\Delta p d u C$ mutant in ATCC 23272 background & This study \\
\hline PRB94 & $\Delta p d u C$ mutant in ATCC PTA-6475 background & This study \\
\hline PRB104 & $\Delta d h a T$ mutant in ATCC PTA-6475 background & This study \\
\hline \multicolumn{3}{|l|}{ E. coli strains } \\
\hline $\mathrm{DH} 5 \alpha$ & Strain used for MIC assays & Laboratory stock \\
\hline TW6375 & Enteropathogenic strain & $\begin{array}{l}\text { T. Whittam, Michigan State University, } \\
\text { East Lansing, MI }\end{array}$ \\
\hline TW951 & Enterohaemorrhagic strain & T. Whittam \\
\hline BW25113 & Background strain for JW3933-3 & $\begin{array}{l}\text { Coli Genetic Stock Center } \\
\text { (Datsenko \& Wanner, 2000) }\end{array}$ \\
\hline \multicolumn{3}{|l|}{ Other strains } \\
\hline $\begin{array}{l}\text { Clostridium difficile } \\
\text { CD630 }\end{array}$ & Wild-type & $\begin{array}{l}\text { A. L. Sonenshein, Tufts University, } \\
\text { Medford, MA }\end{array}$ \\
\hline $\begin{array}{l}\text { B. subtilis RB247 } \\
\text { (JH642) }\end{array}$ & Wild-type & Dean et al. (1977) \\
\hline C. rodentium DBS 120 & Wild-type & $\begin{array}{l}\text { V. Young, University of Michigan, } \\
\text { Ann Arbor, MI (Schauer \& Falkow, 1993) }\end{array}$ \\
\hline
\end{tabular}

version 1.0.1 (Operon), which contained probes specific for three $E$. coli strains, K-12 (MG1655), O157: H7 Sakai and O157: H7 EDL-933. Overnight cultures of $E$. coli were diluted 1:100 in $25 \mathrm{ml} \mathrm{LB}$ broth and grown to mid-exponential phase $\left(\mathrm{OD}_{600} 0.25\right)$ under hypoxic conditions $\left(2 \% \mathrm{O}_{2}\right)$ with shaking at 250 r.p.m. Reuterin-containing cell-free supernatant was added to cultures to yield a final concentration of approximately 5 units reuterin $\mathrm{ml}^{-1}$. This concentration is sufficient to slow growth of $E$. coli without being lethal. LB broth $(2 \times)$ was added at the same time to maintain the same nutrient concentration. Glycerol $(250 \mathrm{mM})$ was added to identical cultures as controls. Cells were allowed to grow for one doubling before samples were taken for analysis. Sample preparation, RNA isolation using RNeasy RNA isolation kits (Qiagen), indirect cDNA labelling with Cy3- or Cy5-labelled aminoallyl dUTP, and slide hybridization were performed as described previously (Britton et al., 2002; Britton, 2003). Slides were scanned on a GenePix 4000B scanner (Axon Instruments). Five biological replicates were analysed. Microarray data were analysed using iterative outlier analysis with three iterations, as previously described (Britton et al., 2002; Uicker et al., 2006). Genes that had expression values three standard deviations or more away from the mean of the population were considered statistically significant.

Sensitivity of $E$. coli oxyR mutant strains to reuterin and hydrogen peroxide. E. coli strains JW3933-3 and BW25113 were grown overnight at $37{ }^{\circ} \mathrm{C}$ in LB broth and diluted to approximately $10^{4}$ cells $\mathrm{ml}^{-1}$. MIC assays were performed to test sensitivity of the cells to reuterin and hydrogen peroxide. To test sensitivity to reuterin, twofold serial dilutions of reuterin-containing cell-free supernatant samples were generated and combined with $E$. coli suspension as described above. To test sensitivity to hydrogen peroxide, twofold serial dilutions of hydrogen peroxide (Sigma-Aldrich) were prepared with water in 96-well $0.4 \mathrm{ml}$ deep-well flat-bottomed plates (Nalge Nunc) in a total volume of $150 \mu \mathrm{l}$ per well; the final concentration of hydrogen peroxide ranged from $1.2 \mathrm{mM}$ to $1.2 \mu \mathrm{M}$. A $150 \mathrm{ml}$ volume of the E. coli suspension was added to each well as described above. The 96-well plates were incubated aerobically at $37{ }^{\circ} \mathrm{C}$ overnight. Five biological replicates were analysed.

Mutant construction. Mutant L. reuteri ATCC 23272 and L. reuteri ATCC PTA-6475 strains for the glycerol dehydratase subunit $\gamma$ gene ( $p d u C$, also known as $g u p C$ ) and the 1,3-propanediol oxidoreductase gene (dhaT) were constructed using the system developed by Russell \& Klaenhammer (2001) and modified for use in L. reuteri (Walter et al., 2005; Whitehead et al., 2008). To create the $\Delta p d u C$ mutant strains, a $356 \mathrm{bp}$ internal fragment $(+37$ to +392$)$ was PCRamplified from the $p d u C$ gene in ATCC 23272 using primers LS74 (5'-TGACTGGATCCTAACGGCCAATTCATCAAGATAC-3') and LS87 (5' -TGACTGAATTCTTGATAGCCATAATCATTTCACC-3'), and a 367 bp internal fragment $(+43$ to +409$)$ was PCR-amplified from ATCC PTA-6475 using primers LS67 (5'-TGACTGGATCCTAATTTGGTCCTGGTGTTATTGC- ${ }^{\prime}$ ) and LS89 (5'-TGACTGAATTCTCAATGGTGGAAGTGGATTC- ${ }^{\prime}$ ). The fragments were cloned into pORI28 to create plasmids pLS46 for ATCC 23272 and pLS47 for ATCC PTA-6475; these plasmids were then used to generate $\triangle p d u C$ mutant $L$. reuteri strains $\mathrm{PRB} 90$ and PRB94, as previously described (Whitehead et al., 2008). To create the $\Delta d h a T$ mutant strains, a $194 \mathrm{bp}$ fragment $(+43$ to +236$)$ was PCRamplified from the dhaT gene in L. reuteri ATCC 55730 using primers LS67 (5' -TGACTGGATCCTAATTTGGTCCTGGTGTTATTGC-3') and LS68 (5'-TGACTGAATTCTTCCGGATCTTAGGGTTAGG-3') and cloned into pORI28 to create plasmid pLS39. The dhaT gene sequence is $99 \%$ identical among $L$. reuteri ATCC 23272, L. reuteri ATCC PTA-6475 and L. reuteri ATCC 55730, and therefore pLS39 
could be used to generate $\Delta d h a T$ mutants in both $L$. reuteri ATCC 23272 and L. reuteri ATCC PTA-6475 backgrounds to create strains PRB81 and PRB104, respectively.

Inhibition of free thiol groups. The reduction of Ellman's reagent, or 5,5'-dithiobis-(2-nitrobenzoic acid) (DTNB) by free thiol groups releases 5-thio-2-nitrobenzoic acid (TNB; $A_{\max } 412 \mathrm{~nm}$ ) and can be monitored spectrophotometrically (Ellman, 1959). Increasing amounts of reuterin produced from ATCC PTA-6475 were prepared in water in a final volume of $125 \mu \mathrm{l}$ and then mixed with $8.3 \mu \mathrm{l} 3 \mathrm{mM}$ glutathione (GSH) and $108.3 \mu 1100 \mathrm{mM}$ phosphate buffer, $\mathrm{pH} 7.0$, in 96-well plates. After $1 \mathrm{~h}$ at room temperature, $8.3 \mu \mathrm{l} 15 \mathrm{mM}$ DTNB was added and $A_{412}$ was measured. Samples and standard curves were done in duplicate. Control reactions with no GSH had no absorbance. Iodoacetamide, which is an irreversible thiol-modifying compound, was assayed as a positive control. PRB94, the glycerol dehydratase $(\Delta p d u C)$ mutant of ATCC PTA-6475, was used as a negative control.

HPLC. Reuterin was produced, and reuterin-containing cell-free supernatant from early stationary phase cultures of ATCC 55730 was prepared and concentrated fivefold under nitrogen. $\mathrm{H}_{2} \mathrm{SO}_{4}$ was added to a final concentration of $10 \mathrm{mM}$. The samples were injected using a $200 \mu \mathrm{l}$ loop and run through a $300 \times 7.8 \mathrm{~mm}$ Bio-Rad Aminex HPX$87 \mathrm{H}$ ion exclusion column at a flow rate of $0.6 \mathrm{ml} \mathrm{min}^{-1}$ at room temperature using $10 \mathrm{mM}$ de-gassed $\mathrm{H}_{2} \mathrm{SO}_{4}$ as eluent. Components were detected with Breeze software using model 2487 UV absorbance $(210 \mathrm{~nm})$ and 2414 refractive index detectors (Waters), before being collected in a 96 -well plate $(300 \mu \mathrm{l}$ per well).

Co-incubation of $\boldsymbol{L}$. reuteri with other bacteria. E. coli, B. subtilis and $C$. rodentium cells were grown in liquid culture for $24 \mathrm{~h}$, pelleted, washed twice with $50 \mathrm{mM}$ potassium phosphate buffer ( $\mathrm{pH} 7.4)$, and resuspended in potassium buffer at approximately $50 \mathrm{mg}$ cells $\mathrm{ml}^{-1}$. The appropriate amounts of bacteria were combined with $150 \mathrm{mg} L$. reuteri cells in potassium buffer in a final volume of $15 \mathrm{ml}$ in $15 \mathrm{ml}$ screw-capped tubes. Cell mixtures were then pelleted, resuspended in $15 \mathrm{ml} 250 \mathrm{mM}$ glycerol, and incubated at $37{ }^{\circ} \mathrm{C}$ for $2 \mathrm{~h}$. Reuterin was collected from the supernatants by pelleting the cells and filtering the supernatants through $0.22 \mu \mathrm{m}$ pore-size filters (Millipore).

In order to determine whether the viability of $E$. coli was required for the increase in reuterin levels, E. coli cells were killed via heat or UV irradiation. For heat-killed E. coli, cells were boiled for $10 \mathrm{~min}$. For UV-killed E. coli, cells were washed in $50 \mathrm{mM}$ potassium phosphate

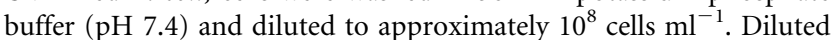
cells in a Petri dish were then exposed to short-wave UV light at a distance of $1 \mathrm{~cm}$ for $60 \mathrm{~s}$. Loss of viability of E. coli was confirmed by plating cells onto LB agar and incubating overnight at $37^{\circ} \mathrm{C}$. E. coli (50 $\mathrm{mg}$ ) and L. reuteri $(150 \mathrm{mg}$ ) were then combined, resuspended in $250 \mathrm{mM}$ glycerol in a final volume of $15 \mathrm{ml}$, and incubated at $37{ }^{\circ} \mathrm{C}$ for $2 \mathrm{~h}$ as described above.

\section{RESULTS}

\section{Exposure of $E$. coli cells to reuterin results in the increased expression of genes that encode proteins containing thiol groups and genes involved in the oxidative stress response}

We were interested in identifying the mechanism of action by which reuterin exerts its antimicrobial effects. Using DNA microarrays to monitor E. coli gene expression we found that many genes involved in the oxidative stress response were induced in response to reuterin exposure.
E. coli cells were grown to mid-exponential phase under hypoxic conditions $\left(2 \% \mathrm{O}_{2}\right)$ and exposed to a sublethal concentration of reuterin that caused a mild reduction in growth rate. Gene expression profiles of cells exposed to reuterin compared with those of untreated cells were determined using DNA microarrays. Table 2 lists the 33 genes whose expression was most strongly induced in response to reuterin exposure. A full list of the genes induced by reuterin is available in Supplementary Table S1. Many of the genes that were significantly overexpressed in reuterin-treated cells encode proteins that require thiol groups for their function (e.g. reductases). In addition, several genes that were induced by $\mathrm{H}_{2} \mathrm{O}_{2}$ in $E$. coli were upregulated and are highlighted in Table 3, including thioredoxin, glutaredoxin and hydroperoxide reductase (Zheng et al., 2001). The gene most highly overexpressed in response to reuterin was $b h s$, which is also highly induced by exposure to $\mathrm{H}_{2} \mathrm{O}_{2}$; bhs has been shown to be involved in stress resistance and biofilm formation in E. coli (Zhang et al., 2007). yqhD, another gene highly expressed as a result of reuterin exposure, encodes an aldehyde reductase involved in protecting against harmful aldehydes produced by lipid peroxidation. Overexpression of $y q h D$ increases the resistance of $E$. coli to the effects of reactive oxygen molecules (Perez et al., 2008). Overall, genes regulated by hydrogen peroxide were eightfold over-represented in the genes that were induced by reuterin compared with what would be expected if 33 genes were selected randomly from the E. coli genome. These results indicate that reuterin is exerting an oxidative stress response upon cells, most likely by acting as a thiolmodifying agent in the aldehyde form.

\section{An E. coli strain defective in the OxyR-mediated oxidative stress response is more sensitive to reuterin}

Exposure of E. coli to reuterin induced the expression of several genes that are under the transcriptional control of the positive transcriptional regulator OxyR, which upregulates many genes in response to oxidative stress (including hydrogen peroxide). Disruption of the $\operatorname{oxy} R$ gene results in increased sensitivity to agents causing oxidative stress, notably hydrogen peroxide (Christman et al., 1985). The expression profiles from E. coli exposed to reuterin overlapped significantly with profiles from $E$. coli exposed to $\mathrm{H}_{2} \mathrm{O}_{2}$, leading us to investigate whether $\Delta o x y R$ mutant cells are also more sensitive to reuterin. We found that an E. coli $\Delta \operatorname{oxyR}$ mutant (JW3933-3) was four times more sensitive to reuterin than the isogenic wild-type parental strain as determined by MIC assay, further supporting the suggestion that reuterin is exerting oxidative stress. The same $\Delta o x y R$ mutant strain was eight times more sensitive to $\mathrm{H}_{2} \mathrm{O}_{2}$ than wild-type cells, indicating that the degree of sensitivity to reuterin and $\mathrm{H}_{2} \mathrm{O}_{2}$ is similar. These results suggest that reuterin induces oxidative stress in E. coli. 
Table 2. The most highly overexpressed genes in E. coli cells treated with sublethal concentrations of reuterin

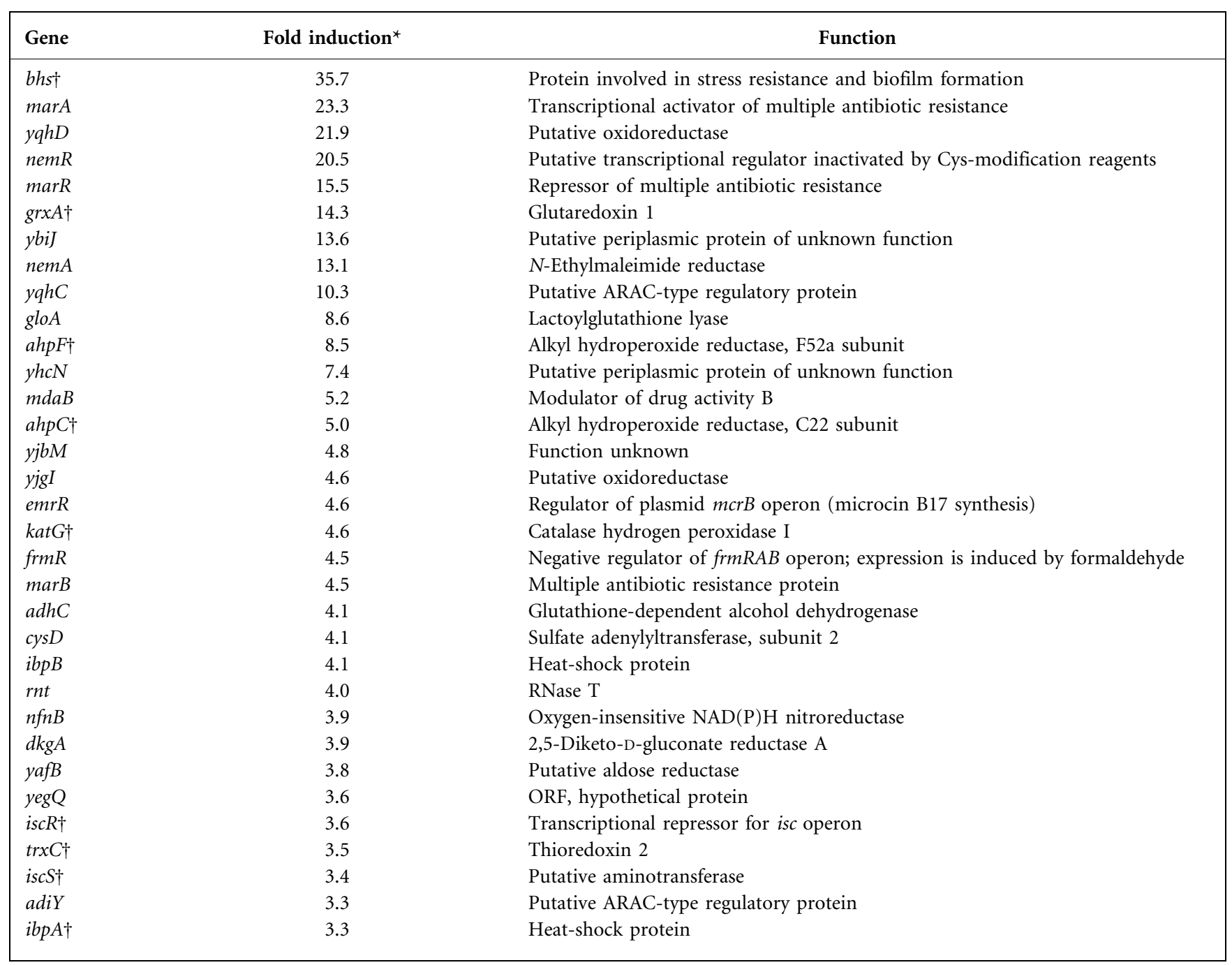

${ }^{\star}$ Increased level of expression in reuterin-treated cells versus untreated cells.

$\dagger$ Genes overexpressed in response to hydrogen peroxide (Zheng et al., 2001).

\section{Addition of an exogenous thiol group can suppress the antimicrobial effects of reuterin}

To further test if reuterin could interact with thiol groups we asked whether the addition of excess cysteine to media could inhibit the antimicrobial activity of reuterin. MIC assays for reuterin against $E$. coli were conducted in the presence of $600 \mu \mathrm{M}$ cysteine. With the addition of cysteine, only the most concentrated level of reuterin (32 units $\mathrm{ml}^{-1}$ ) was able to suppress the growth of E. coli, representing a 16 -fold increase in the MIC value for reuterin with respect to $E$. coli without the amino acid added $\left(2\right.$ units $\mathrm{ml}^{-1}$ ). The addition of the amino acids valine or serine at $600 \mu \mathrm{M}$ concentrations had no effect on reuterin activity, indicating that reuterin was interacting with the thiol group of cysteine and not the free amino group. We also confirmed the inhibition of reuterin activity by cysteine in a MIC assay using Clostridium difficile strain CD630. The ability of cysteine to detoxify reuterin further supports the hypothesis that reuterin induces oxidative stress through interaction with thiol groups.

\section{Glycerol dehydratase is required for reuterin production}

The glycerol dehydratase of $L$. reuteri is a cobalamindependent enzyme composed of three subunits $(\alpha, \beta$ and $\gamma)$ and catalyses the conversion of glycerol to reuterin (3HPA). To assess whether this is the sole pathway for reuterin production in $L$. reuteri, we created a disruption in the $p d u C$ gene, which encodes the large subunit $\gamma$ of glycerol dehydratase in two L. reuteri strains, ATCC 23272, which is the type strain originally isolated from human faeces (Kandler et al., 1980), and ATCC PTA-6475, which was isolated from breast milk and has been shown to possess immunomodulatory activity (Lin et al., 2008). 
Table 3. Overlap between genes overexpressed in response to hydrogen peroxide treatment and in response to reuterin treatment

\begin{tabular}{|lcl|}
\hline Gene & Fold induction ${ }^{\star}$ & \multicolumn{1}{c|}{ Function } \\
\hline$b h s$ & 35.7 & Protein involved in stress resistance and biofilm formation \\
$g r x A$ & 14.3 & Glutaredoxin 1 \\
$a h p F$ & 8.5 & Alkyl hydroperoxide reductase, F52a subunit \\
$a h p C$ & 5.0 & Alkyl hydroperoxide reductase, C22 subunit \\
$k a t G$ & 4.6 & Catalase hydrogen peroxidase I \\
$i s c R$ & 3.6 & Transcriptional repressor for isc operon \\
$t r x C$ & 3.5 & Thioredoxin 2 \\
$i s c S$ & 3.4 & Putative aminotransferase \\
$i b p A$ & 3.3 & Heat-shock protein \\
$i s c U$ & 2.8 & Iron-sulfur cluster assembly scaffold protein \\
$i s c A$ & 2.8 & Iron-sulfur cluster assembly protein \\
$i s c X$ & 2.6 & Iron-sulfur cluster assembly protein \\
$y e e D$ & 2.1 & Function unknown \\
\end{tabular}

${ }^{\star}$ Increased level of expression in reuterin-treated cells versus untreated cells.

After overnight growth in MRS broth, $\Delta p d u C$ mutant cells and wild-type cells were incubated in aqueous glycerol solution, and reuterin production was measured using both an adapted colorimetric assay (Doleyres et al., 2005) and a MIC bioassay (Chung et al., 1989). The mutant strains did not produce any detectable reuterin according to either assay, demonstrating that glycerol dehydratase is required for reuterin production in $L$. reuteri (Fig. 2).

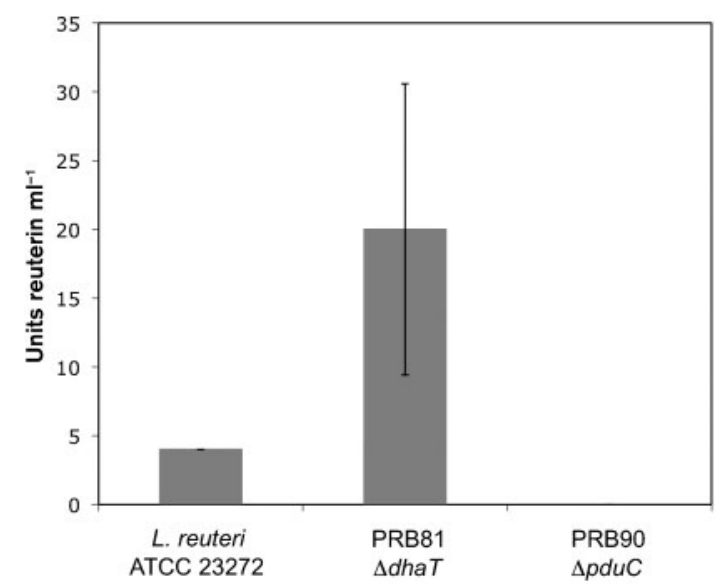

Fig. 2. Reuterin production in L. reuteri strains mutant for enzymes involved in glycerol metabolism. Inactivation of 1,3-propanediol oxidoreductase in strain PRB81 ( $\Delta d h a T)$ produced higher levels of reuterin as compared with wild-type strain L. reuteri ATCC 23272 during late stationary phase, as measured by MIC assay in three replicate experiments. Inactivation of glycerol dehydratase $(\Delta p d u C)$ in strain PRB90 resulted in no detectable reuterin production. Units reuterin $\mathrm{ml}^{-1}$ were determined from the fold dilution of the reuterin supernatant that was still able to inhibit the growth of $E$. coli in the MIC assay. Error bars, SD. These results were independently confirmed using the colorimetric assay (data not shown).
These results confirm and extend those published by Morita et al. (2008), in which the entire genomic region containing the genes encoding the three glycerol dehydratase subunits was deleted in L. reuteri strain JCM $1112^{\mathrm{T}}$, resulting in elimination of reuterin production capability.

We were also interested in determining if disruption of the dhaT gene, encoding 1,3-propanediol oxidoreductase, would lead to overproduction of reuterin. Reuterin is normally converted to 1,3-propanediol by 1,3-propanediol oxidoreductase. We created deletion mutants in strains ATCC 23272 and ATCC PTA- 6475 by disrupting the gene encoding this enzyme and measured their ability to produce reuterin compared with wild-type cells. An increase in reuterin levels two- to eightfold over wild-type was observed for stationary-phase cells (Fig. 2); the difference in reuterin production between mutant and wild-type cells increased as cells moved into later stationary phase. Little or no difference in reuterin levels was observed between the $\Delta d h a T$ mutant and wild-type cells in exponential phase and early stationary phase.

\section{Reuterin can inhibit free thiol groups in an in vitro assay}

One proposed mechanism by which aldehydes cause stress in cells is via their ability to react with thiol and primary amine groups of proteins (Vollenweider \& Lacroix, 2004). Using an assay that detects the presence of free thiol groups, we investigated whether reuterin can directly modify thiol groups. Ellman's reagent (DTNB) contains a disulfide bond that can be reduced by free thiol groups, and has been used extensively to quantify free thiol levels in a variety of samples (Ellman, 1959). DTNB reduction releases TNB, which can be monitored spectrophotometrically at $412 \mathrm{~nm}$. Increasing amounts of reuterin produced from ATCC PTA-6475 were mixed with glutathione for $1 \mathrm{~h}$ prior to adding this mixture to 
Ellman's reagent and monitoring TNB levels. Iodoacetamide, a compound that irreversibly interacts with thiol groups, was used as a positive control for thiol inhibition. The glycerol dehydratase $(\Delta p d u C)$ mutant of ATCC PTA-6475 was used to control for any compounds other than reuterin that may affect this assay. Reuterin was able to inhibit the reduction of Ellman's reagent in a concentration-dependent manner, similar to iodoacetamide (Fig. 3). The need for increased levels of reuterin to inhibit the reaction compared with iodoacetamide likely reflects the fact that the reaction of reuterin with thiol groups is reversible (see Discussion). As expected, the $\Delta p d u C$ mutant did not produce any compound capable of inhibiting TNB production, demonstrating that the effect was specific to the production of reuterin.

\section{Antimicrobial activity corresponds to the presence of reuterin and not acrolein}

Dehydration of reuterin generates the highly toxic compound acrolein (Vollenweider \& Lacroix, 2004). Although the conditions that we used to produce reuterin should result in a 3:1 ratio of HPA hydrate to reuterin, we wanted to rule out the possibility that small amounts of acrolein were producing the observed killing effect. Resting $L$. reuteri cells were incubated in aqueous glycerol to produce reuterin; the reuterin-containing supernatant was then subjected to HPLC to separate the components. Fractions were collected and tested for antimicrobial activity using the MIC bioassay and the ability to inhibit the reduction of DTNB by glutathione. The only two peaks detected in the supernatant corresponded to glycerol and reuterin. Antimicrobial activity and the ability to inhibit DTNB reduction were found only in the HPLC fractions that contained reuterin; we did not detect these activities with the fraction that would contain acrolein if present (Fig. 4). This indicates that under our reuterin production conditions, $L$. reuteri cells are not producing levels of acrolein that are deleterious to cell growth.

\section{Reuterin production is increased by interaction with a variety of bacteria}

Reuterin production in $L$. reuteri is stimulated when cells are co-cultured with a variety of other microbes, including bacterial, protozoan and fungal species (Chung et al., 1989). This indicates that interaction with other bacteria in the gastrointestinal tract may trigger reuterin production in vivo. To address the mechanism by which other bacteria stimulate reuterin production we asked whether or not co-culturing of the bacteria was required for this stimulation. We found that co-culturing is not necessary; direct interaction with other micro-organisms during incubation of $L$. reuteri in aqueous glycerol solution is sufficient to produce this stimulation. $L$. reuteri ATCC 23272 and E. coli DH5 $\alpha$ were grown overnight to stationary phase, spun down to remove culture supernatant, and then mixed together in aqueous glycerol solution. Increasing amounts of $E$. coli $\mathrm{DH} 5 \alpha$ incubated with $L$. reuteri produced a corresponding increase in reuterin levels (Fig. 5). This increase was observed with up to six times the amount (in milligrams) of E. coli DH5 $\alpha$ compared with that of $L$. reuteri. E. coli $\mathrm{DH} 5 \alpha$ has no ability to produce reuterin on its own (data not shown). This stimulation was observed for all L. reuteri strains tested, including ATCC 23272, ATCC PTA6475 and ATCC 55730. In addition to E. coli DH5 $\alpha$, stimulation of reuterin production was achieved by coincubation with a variety of bacteria, including B. subtilis, the mouse pathogen $C$. rodentium, enterohaemorrhagic $E$. coli and enteropathogenic E. coli (data not shown).

\section{The viability of $E$. coli is not required for stimulation of reuterin production}

To address the mechanism through which E. coli increases reuterin production in $L$. reuteri, we tested whether the

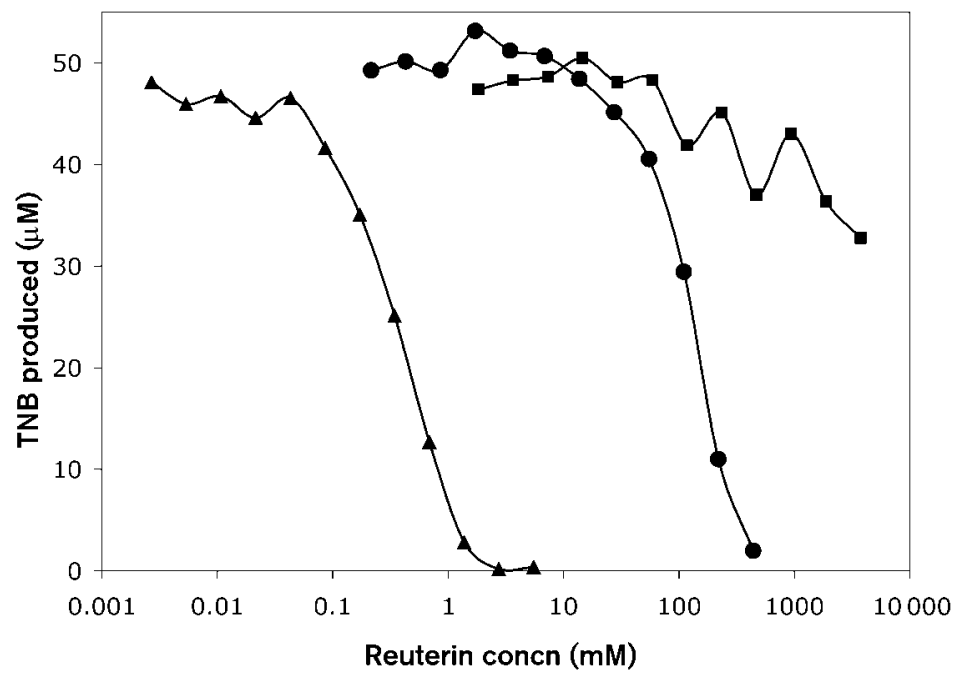

Fig. 3. Effect of reuterin on thiol-mediated reduction of Ellman's reagent. Increasing amounts of iodoacetamide $(\mathbf{A})$, reuterin $(\mathbf{O})$ or control supernatant ( $\boldsymbol{\square})$ (derived from $L$. reuteri PRB94 cells, which have deletions of the pduC gene) were incubated in phosphate buffer with glutathione for $1 \mathrm{~h}$, after which time Ellman's reagent was added and the amount of TNB produced was determined. There was no detectable TNB production when glutathione was omitted. 


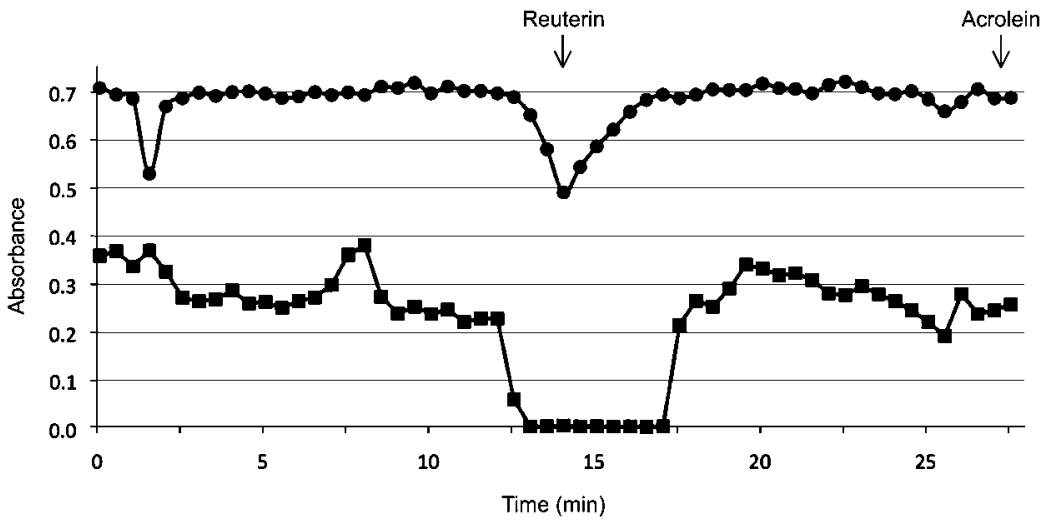

Fig. 4. HPLC fractionation of $L$. reuteri supernatants. HPLC fractions of reuterin supernatant produced from $L$. reuteri ATCC PTA-6475 were assayed for inhibition of DTNB reduction by free thiol groups $\left(\bullet, A_{412}\right)$ and inhibition of E. coli growth $\left(\boldsymbol{\square}, \mathrm{OD}_{600}\right.$; from modified MIC assay). Pure reuterin and acrolein were run on the HPLC column and detected at 14 and $27.25 \mathrm{~min}$, respectively (indicated by arrows), in agreement with earlier reports by others. Antimicrobial activity and thiol inhibition corresponded with reuterin but not acrolein.

viability of the E. coli cells was necessary for stimulation of reuterin synthesis. E. coli DH5 $\alpha$ cells were heat-killed either by boiling or by prolonged exposure to UV irradiation before incubation with $L$. reuteri in glycerol solution. Reuterin levels were measured by both MIC and colorimetric assays (Fig. 6). Full stimulation was observed using UV-killed E. coli but not the heat-killed cells (Fig. 6), indicating that although viability is not a requirement, treatment with extreme heat eliminates the ability of the $E$. coli to increase reuterin production.

\section{DISCUSSION}

The antimicrobial compound reuterin has been proposed to be important for the ability of certain probiotic $L$. reuteri strains to exert beneficial properties on their hosts. Here we present evidence that the broad-spectrum antimicrobial activity of reuterin is due to $3-\mathrm{HPA}$, which is predicted to be highly reactive towards thiol groups and primary amines. Microarray analysis of cells treated with reuterin indicated that cells were undergoing oxidative stress. Reuterin assays conducted with oxyR mutant strains demonstrated that the OxyR oxidative stress response was required for $E$. coli to most effectively resist the effects of reuterin. Exogenously applied cysteine, but not other amino acids, could counteract the effects of reuterin. This indicates that the interaction of reuterin with thiol groups but not with primary amines was responsible for the growth inhibition. These results all indicate that the bioactive component of reuterin is the aldehyde form interacting with thiol groups of small molecules and proteins, rather than the HPA dimer inhibiting ribonucleotide reductase as a competitive inhibitor. Previous work had suggested that the HPA dimer was not favoured as the bioactive component, since it is only found in concentrations of reuterin greater than $1 \mathrm{M}$ and is a minor component at relevant antimicrobial concentrations (Vollenweider et al., 2003). In addition, the inhibition of ribonucleotide reductase would activate a strong SOS response in $E$. coli, which was not observed in our global gene expression experiments.

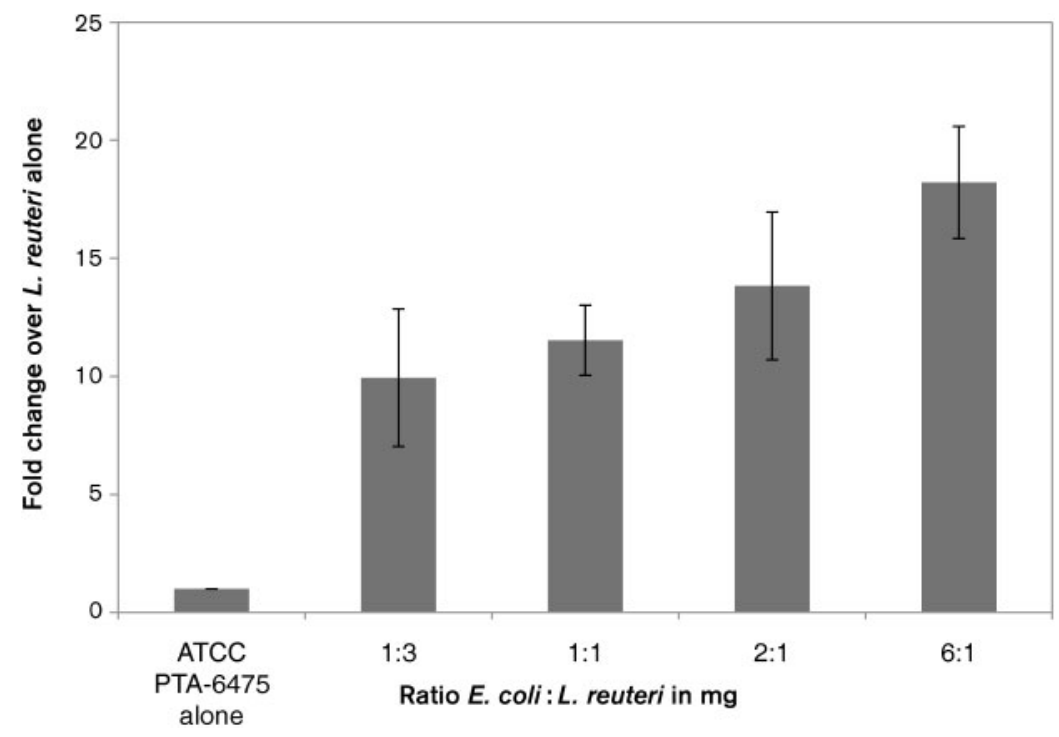

Fig. 5. Reuterin production is increased by interaction with $E$. coli. Increasing amounts of E. coli $\mathrm{DH} 5 \alpha$ incubated with $L$. reuteri ATCC PTA-6475 in glycerol solution produced increased reuterin levels. Reuterin levels were monitored by colorimetric change at $A_{560}$, as described by Circle et al. (1945), in three replicate experiments. The wild-type strain ATCC PTA-6475 was incubated with the increasing amounts of $E$. coli cells indicated on the $x$ axis. The fold change over the reuterin levels produced by ATCC PTA-6475 in the absence of $E$. coli is represented on the $y$ axis. Error bars, SD. 

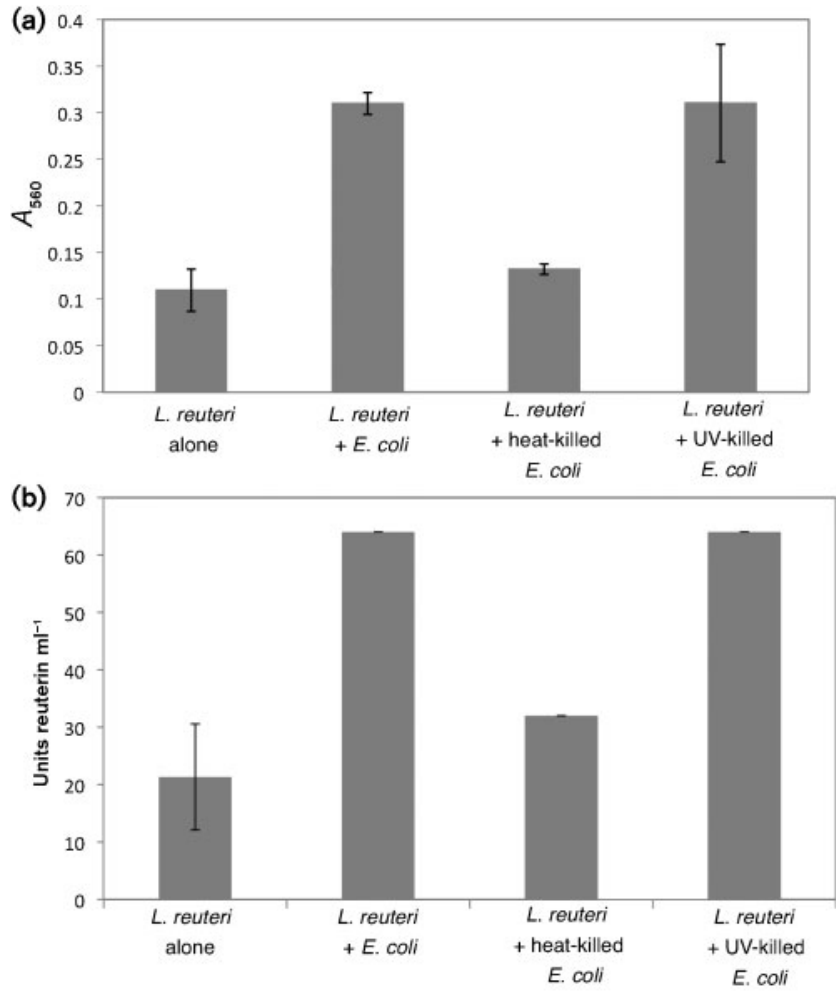

Fig. 6. Viability of $E$. coli is not required to induce higher levels of reuterin accumulation. Wild-type $L$. reuteri ATCC PTA-6475 cells were incubated in the presence of UV-killed or heat-killed $E$. coli cells and the levels of reuterin production were measured using the colorimetric assay (a) and MIC assay (b). Units reuterin $\mathrm{ml}^{-1}$ were determined from the fold dilution of the reuterin supernatant that was still able to inhibit the growth of $E$. coli in the MIC assay. The data presented are from three replicate experiments. Error bars, SD.

One concern regarding the use of reuterin as an antimicrobial agent is its ability to create the highly toxic compound acrolein by dehydration of reuterin. We verified that the antimicrobial activity that we were observing using our reuterin production conditions was in fact due to reuterin and not to other compounds such as acrolein. Using HPLC we determined that the bioactive component of reuterin was always associated with a peak corresponding to reuterin. Antimicrobial activity was not detected with the fraction that would contain acrolein. This result eliminates any concern that low levels of acrolein were contaminants of the reuterin preparations tested in this study.

The discovery that reuterin production or secretion can be stimulated by interaction with other bacteria suggests that L. reuteri utilizes reuterin to gain a competitive advantage in the intestinal tract. While previous work had shown that co-culturing produces this stimulatory effect (Chung et al., 1989), we have demonstrated that simply mixing stationary phase $L$. reuteri with a number of other types of bacteria in a concentrated glycerol solution was sufficient. Because the bacteria were washed prior to being mixed together and viability is not required, we can mostly rule out the accumulation of a secondary metabolite as the mechanism of stimulation. The fact that heat-killed bacteria are not able to support reuterin stimulation while UV-killed bacteria retain this ability suggests that a heat-labile component is involved in the stimulation response. At this time we do not know if additional reuterin is being synthesized or the increase is due to more reuterin being released from the cell.

One issue concerning reuterin as an antimicrobial agent that would be bioactive against pathogens is the relatively high levels of reuterin required for killing activity in vitro. We estimate that approximately $1 \mathrm{mM}$ reuterin is required to prevent bacterial growth in vitro, similar to concentrations that have been reported elsewhere (Cleusix et al., 2007; Spinler et al., 2008). NMR analysis of the forms of reuterin present at different concentrations indicates that a $1 \mathrm{mM}$ solution of reuterin would contain $750 \mu \mathrm{M} \mathrm{HPA}$ hydrate and only $250 \mu \mathrm{M}$ of the bioactive aldehyde 3-HPA (Vollenweider et al., 2003). The requirement for high levels of reuterin is likely due to the fact that reactions between thiol groups and aldehydes forming hemithioacetals are reversible. The 3-hydroxy substituent of reuterin also accentuates the electrophilicity of the aldehyde and therefore its propensity towards hydration, which explains, in part, why the HPA hydrate form predominates in vitro under aqueous conditions. Thus, the environment in which 3-HPA exists will greatly affect how much of the bioactive aldehyde form exists. At this time we do not know how conditions within the intestinal tract would influence the balance of the aldehyde and HPA hydrate forms.

It seems unlikely that $L$. reuteri would be able to produce such high levels throughout the intestinal tract and have a systemic killing effect on a pathogen. A more likely function of reuterin is perhaps to provide a localized antimicrobial effect in which production of reuterin could provide a competitive advantage in the intestinal tract. $L$. reuteri itself is highly resistant to the effects of reuterin and therefore could create a zone of growth inhibition to compete with other organisms in the gastrointestinal tract. Future studies using the mutants described in this manuscript will address the ability of reuterin to enhance colonization of $L$. reuteri as well as its role in evoking beneficial effects in animal models.

\section{ACKNOWLEDGEMENTS}

We thank Scott Mulrooney and Piotr Grzyska for HPLC assistance, and Cathy Robinson for analysing the effects of reuterin on Clostridium difficile. We appreciate the support of Eamonn Connolly and BioGaia for access to probiotic L. reuteri strains and helpful research discussions. We also thank Abraham L. Sonenshein (Tufts University, Medford, MA) for providing us with Clostridium difficile CD630. This work was supported by grants from The Gerber Foundation and the Michigan State Center for Microbial Pathogenesis. 


\section{REFERENCES}

Arques, J. L., Fernandez, J., Gaya, P., Nunez, M., Rodriguez, E. \& Medina, M. (2004). Antimicrobial activity of reuterin in combination with nisin against food-borne pathogens. Int J Food Microbiol 95, 225-229.

Arques, J. L., Rodriguez, E., Nunez, M. \& Medina, M. (2008). Antimicrobial activity of nisin, reuterin, and the lactoperoxidase system on Listeria monocytogenes and Staphylococcus aureus in cuajada, a semisolid dairy product manufactured in Spain. J Dairy Sci 91, 70-75.

Baba, T., Ara, T., Hasegawa, M., Takai, Y., Okumura, Y., Baba, M., Datsenko, K. A., Tomita, M., Wanner, B. L. \& Mori, H. (2006). Construction of Escherichia coli K-12 in-frame, single-gene knockout mutants: the Keio collection. Mol Syst Biol 2, 2006.0008.

Bergholz, T. M., Wick, L. M., Qi, W., Riordan, J. T., Ouellette, L. M. \& Whittam, T. S. (2007). Global transcriptional response of Escherichia coli $\mathrm{O} 157: \mathrm{H} 7$ to growth transitions in glucose minimal medium. BMC Microbiol 7, 97.

Britton, R. A. (2003). DNA microarrays and bacterial gene expression. Methods Enzymol 370, 264-278.

Britton, R. A., Eichenberger, P., Gonzalez-Pastor, J. E., Fawcett, P., Monson, R., Losick, R. \& Grossman, A. D. (2002). Genome-wide analysis of the stationary-phase sigma factor (sigma-H) regulon of Bacillus subtilis. J Bacteriol 184, 4881-4890.

Christman, M. F., Morgan, R. W., Jacobson, F. S. \& Ames, B. N. (1985). Positive control of a regulon for defenses against oxidative stress and some heat-shock proteins in Salmonella typhimurium. Cell 41, 753-762.

Chung, T. C., Axelsson, L., Lindgren, S. E. \& Dobrogosz, W. J. (1989), In vitro studies on reuterin synthesis by Lactobacillus reuteri. Microb Ecol Health Dis 2, 137-144.

Circle, S. J., Stone, L. \& Boruff, C. S. (1945). Acrolein determination by means of tryptophan. Ind Eng Chem Res 17, 259-262.

Cleusix, V., Lacroix, C., Vollenweider, S., Duboux, M. \& Le Blay, G. (2007). Inhibitory activity spectrum of reuterin produced by Lactobacillus reuteri against intestinal bacteria. BMC Microbiol 7, 101.

Datsenko, K. A. \& Wanner, B. L. (2000). One-step inactivation of chromosomal genes in Escherichia coli K-12 using PCR products. Proc Natl Acad Sci U S A 97, 6640-6645.

Dean, D. R., Hoch, J. A. \& Aronson, A. I. (1977). Alteration of the Bacillus subtilis glutamine synthetase results in overproduction of the enzyme. J Bacteriol 131, 981-987.

Doleyres, Y., Beck, P., Vollenweider, S. \& Lacroix, C. (2005). Production of 3-hydroxypropionaldehyde using a two-step process with Lactobacillus reuteri. Appl Microbiol Biotechnol 68, 467-474.

Ellman, G. L. (1959). Tissue sulfhydryl groups. Arch Biochem Biophys 82, 70-77.

Floch, M. H., Walker, W. A., Guandalini, S., Hibberd, P., Gorbach, S. Surawicz, C., Sanders, M. E., Garcia-Tsao, G., Quigley, E. M. \& other authors (2008). Recommendations for probiotic use -2008. J Clin Gastroenterol 42 (Suppl. 2), S104-S108.

Kandler, O., Setter, K. O. \& Kohl, R. (1980). Lactobacillus reuteri sp. nov., a new species of heterofermentative lactobacilli. Zentralbl Bakteriol Mikrobiol Hyg Abt 1 Orig C1, 264-269.

Lin, Y. P., Thibodeaux, C. H., Pena, J. A., Ferry, G. D. \& Versalovic, J. (2008). Probiotic Lactobacillus reuteri suppress proinflammatory cytokines via c-Jun. Inflamm Bowel Dis 14, 1068-1083.

Luthi-Peng, Q., Dileme, F. B. \& Puhan, Z. (2002). Effect of glucose on glycerol bioconversion by Lactobacillus reuteri. Appl Microbiol Biotechnol 59, 289-296.
Marco, M. L., Pavan, S. \& Kleerebezem, M. (2006). Towards understanding molecular modes of probiotic action. Curr Opin Biotechnol 17, 204-210.

Morita, H., Toh, H., Fukuda, S., Horikawa, H., Oshima, K., Suzuki, T., Murakami, M., Hisamatsu, S., Kato, Y. \& other authors (2008). Comparative genome analysis of Lactobacillus reuteri and Lactobacillus fermentum reveal a genomic island for reuterin and cobalamin production. DNA Res 15, 151-161.

O'Hara, A. M. \& Shanahan, F. (2007). Mechanisms of action of probiotics in intestinal diseases. ScientificWorldJournal 7, 31-46.

Perez, J. M., Arenas, F. A., Pradenas, G. A., Sandoval, J. M. \& Vasquez, C. C. (2008). Escherichia coli YqhD exhibits aldehyde reductase activity and protects from the harmful effect of lipid peroxidation-derived aldehydes. J Biol Chem 283, 7346-7353.

Rosenfeldt, V., Michaelsen, K. F., Jakobsen, M., Larsen, C. N., Møller, P. L., Pedersen, P., Tvede, M., Weyrehter, H., Valerius, N. H. \& Paerregaard, A. (2002a). Effect of probiotic Lactobacillus strains in young children hospitalized with acute diarrhea. Pediatr Infect Dis J 21, 411-416.

Rosenfeldt, V., Michaelsen, K. F., Jakobsen, M., Larsen, C. N., Moller, P. L., Tvede, M., Weyrehter, H., Valerius, N. H. \& Paerregaard, A. (2002b). Effect of probiotic Lactobacillus strains on acute diarrhea in a cohort of nonhospitalized children attending day-care centers. Pediatr Infect Dis J 21, 417-419.

Russell, W. M. \& Klaenhammer, T. R. (2001). Efficient system for directed integration into the Lactobacillus acidophilus and Lactobacillus gasseri chromosomes via homologous recombination. Appl Environ Microbiol 67, 4361-4364.

Savino, F., Pelle, E., Palumeri, E., Oggero, R. \& Miniero, R. (2007). Lactobacillus reuteri (American Type Culture Collection Strain 55730) versus simethicone in the treatment of infantile colic: a prospective randomized study. Pediatrics 119, e124-e130.

Schauer, D. B. \& Falkow, S. (1993). The eae gene of Citrobacter freundii biotype 4280 is necessary for colonization in transmissible murine colonic hyperplasia. Infect Immun 61, 4654-4661.

Spinler, J. K., Taweechotipatr, M., Rognerud, C. L., Ou, C. N., Tumwasorn, S. \& Versalovic, J. (2008). Human-derived probiotic Lactobacillus reuteri demonstrate antimicrobial activities targeting diverse enteric bacterial pathogens. Anaerobe 14, 166-171.

Sriramulu, D. D., Liang, M., Hernandez-Romero, D., Raux-Deery, E., Lunsdorf, H., Parsons, J. B., Warren, M. J. \& Prentice, M. B. (2008). Lactobacillus reuteri DSM 20016 produces cobalamin-dependent diol dehydratase in metabolosomes and metabolizes 1,2-propanediol by disproportionation. J Bacteriol 190, 4559-4567.

Talarico, T. L. \& Dobrogosz, W. J. (1989). Chemical characterization of an antimicrobial substance produced by Lactobacillus reuteri. Antimicrob Agents Chemother 33, 674-679.

Talarico, T. L., Casas, I. A., Chung, T. C. \& Dobrogosz, W. J. (1988). Production and isolation of reuterin, a growth inhibitor produced by Lactobacillus reuteri. Antimicrob Agents Chemother 32, 1854-1858.

Uicker, W. C., Schaefer, L. \& Britton, R. A. (2006). The essential GTPase RbgA (YlqF) is required for $50 \mathrm{~S}$ ribosome assembly in Bacillus subtilis. Mol Microbiol 59, 528-540.

Vollenweider, S. \& Lacroix, C. (2004). 3-Hydroxypropionaldehyde: applications and perspectives of biotechnological production. Appl Microbiol Biotechnol 64, 16-27.

Vollenweider, S., Grassi, G., Konig, I. \& Puhan, Z. (2003). Purification and structural characterization of 3-hydroxypropionaldehyde and its derivatives. J Agric Food Chem 51, 3287-3293.

Walter, J., Chagnaud, P., Tannock, G. W., Loach, D. M., Dal Bello, F., Jenkinson, H. F., Hammes, W. P. \& Hertel, C. (2005). A highmolecular-mass surface protein (Lsp) and methionine sulfoxide 
reductase $\mathrm{B}(\mathrm{MsrB})$ contribute to the ecological performance of Lactobacillus reuteri in the murine gut. Appl Environ Microbiol 71, 979-986.

Weizman, Z., Asli, G. \& Alsheikh, A. (2005). Effect of a probiotic infant formula on infections in child care centers: comparison of two probiotic agents. Pediatrics 115, 5-9.

Whitehead, K., Versalovic, J., Roos, S. \& Britton, R. A. (2008),

Genomic and genetic characterization of the bile stress response of probiotic Lactobacillus reuteri ATCC 55730. Appl Environ Microbiol 74, 1812-1819.

Wickens, K., Black, P. N., Stanley, T. V., Mitchell, E., Fitzharris, P., Tannock, G. W., Purdie, G. \& Crane, J. (2008). A differential effect of 2 probiotics in the prevention of eczema and atopy: a double-blind, randomized, placebo-controlled trial. J Allergy Clin Immunol 122, 788-794.

Zhang, X. S., Garcia-Contreras, R. \& Wood, T. K. (2007). YcfR (BhsA) influences Escherichia coli biofilm formation through stress response and surface hydrophobicity. J Bacteriol 189, 3051-3062.

Zheng, M., Wang, X., Templeton, L. J., Smulski, D. R., LaRossa, R. A. \& Storz, G. (2001). DNA microarray-mediated transcriptional profiling of the Escherichia coli response to hydrogen peroxide. J Bacteriol 183, 4562-4570.

Edited by: P. W. O'Toole 